\title{
DJ-1 modulates UV-induced oxidative stress signaling through the suppression of MEKK1 and cell death
}

\author{
J-S Mo ${ }^{1}$, M-Y Kim ${ }^{1}$, E-J Ann ${ }^{1}$, J-A Hong ${ }^{1}$ and H-S Park ${ }^{\star, 1}$
}

DJ-1 is a multifunctional protein that performs functions in transcriptional regulation and oxidative stress, and the loss of its function is believed to result in the onset of Parkinson's disease (PD). In this study, we report that DJ-1 protects against UVinduced cell death through the suppression of the JNK1 signaling pathway. The results of both binding and kinase studies have revealed that MEKK1 is the direct target of DJ-1. The C-terminus of DJ-1 was crucial to the inhibition of the MEKK1 kinase activity. Wild-type DJ-1 sequesters MEKK1 within the cytoplasm and the L166P mutant facilitates the translocation of MEKK1 toward the nucleus without physical association. Both DJ-1 knockdown and pathogenic L166P mutant were determined to be highly susceptible to the UV-induced activation of the MEKK1-SEK1-JNK1 signaling cascade and cell death. Taken together, our findings show that missense mutation in DJ-1 sensitizes cells to stress-induced cell death through the MEKK1-SEK1-JNK1 signaling pathway, a process, which may trigger the early onset of PD.

Cell Death and Differentiation (2008) 15, 1030-1041; doi:10.1038/cdd.2008.26; published online 29 February 2008

DJ-1 (SP22/CAP-1/RS/PARK7) has been identified as a novel oncogenic protein in transformed NIH3T3 cells, operating in cooperation with H-ras. ${ }^{1}$ Three other groups of cloned rat homolog of DJ-1/SP22/CAP-1, as a major protein appearing at reduced levels in sperm following the exposure of rats to infertility-inducing toxicants, and also as a regulatory subunit (RS) of an RNA-binding multi-protein complex, which stabilizes mRNA in response to cyclic AMP. ${ }^{2-4}$ DJ-1 has recently been shown to be definitively causal in cases of familial Parkinson's disease (PD). Mutations in the DJ-1 gene have been associated with autosomal recessive early onset PD; a homozygous genomic deletion encompassing exon 1-5, a homozygous L166P missense mutation and other homozygous and heterozygous mutations of DJ-1 have been identified in patients with familial or sporadic PD. ${ }^{5-9}$ The crystal structure and yeast two-hybrid data indicate that DJ-1 exists as homodimer harboring domains found in both heat shock protein chaperones and ThiJ/Pfpl proteases. ${ }^{10-12}$ By way of contrast, the L166P mutant exists as a monomer, because it destabilizes the dimer interface. Several lines of evidence suggest that DJ-1 performs a function in the oxidative-stress response ${ }^{13-15}$ and also that its expression is induced by oxidative stresses. ${ }^{16-18}$ The forced knockdown of DJ-1 expression with short interfering RNA (siRNA) results in susceptibility to oxidative stress, endoplasmic reticulum (ER) stress, and proteasome inhibition. ${ }^{19,20}$ The L166P mutant, DJ-1, causes cells to become sensitized to oxidative stress, despite the fact that the pathogenic L166P mutant DJ-1 is highly unstable, and is degraded by the $20 \mathrm{~S} / 26 \mathrm{~S}$ proteasome system. ${ }^{19,21-26}$ Thus far, several lines of evidence also appear to indicate that DJ-1 performs a function in cell death. Firstly, the overexpression of DJ-1 results in PKB/AKT hyperphosphorylation, and enhances cell survival through the suppression of PTEN. ${ }^{27,28}$ Secondly, DJ-1 sequesters Daxx within the nucleus, and prevents it from gaining access to the cytoplasm, which keeps Daxx from binding to and activating its effector kinase, apoptosis signalregulating kinase 1 (ASK1). ${ }^{29}$ Thirdly, in cultured mammalian cells, DJ-1 has been shown to quench reactive oxygen species and, therefore, protects against reactive oxygen species-induced cell death. ${ }^{19,29}$ Nevertheless, despite the many studies conducted regarding the subject, the physiological role of DJ-1 in cell death remains largely unknown. Here, we have demonstrated that DJ-1 modulates the JNK signaling pathway through negative regulation of the functions of mitogen-activated protein kinase/extracellular signal-regulated kinase kinase kinase 1 (MEKK1), through physical interaction.

\section{Results}

DJ-1 suppresses oxidative stress-induced JNK1 activation. To determine the possible role of DJ-1 in the regulation of the c-Jun N-terminal Kinase (JNK1) signaling pathway, we subjected human embryonic kidney 293 (HEK293) cells to transient transfection with an expression plasmid encoding for Flag epitope-tagged DJ-1 (Flag-DJ-1),

${ }^{1}$ Hormone Research Center, School of Biological Sciences and Technology, Chonnam National University, Yongbong-dong, Buk-ku, Gwangju 500-757, Republic of Korea

${ }^{*}$ Corresponding author: H-S Park, School of Biological Sciences and Technology, Chonnam National University, 300, Yongbong-dong, Buk-ku, Gwangju 500-757, Republic of Korea.

Tel: + 8262530 0021; Fax: + 82625302199 ;

E-mail: proteome@jnu.ac.kr

Keywords: DJ-1; MEKK1; JNK1; apoptosis; Parkinson's disease; oxidative stress

Abbreviations: PD, Parkinson's disease; siRNA, short interfering RNA; MEKK1, mitogen-activated protein kinase/extracellular signal-regulated kinase kinase kinase 1; JNK1, c-Jun N-terminal Kinase

Received 29.8.07; revised 31.1.08; accepted 01.2.08; Edited by N Bazan; published online 29.2.08 
and then evaluated the UV-induced activation of JNK1 in the transfected cells. As UV clearly induced JNK1 activation in control cells, this effect was markedly inhibited in the DJ-1 transfected cells (Figure 1a, Supplementary Figure 1A). We then assessed the UV-induced activation of JNK1 in HEK293 cells that had been stably transfected with an expression vector for Flag epitope-tagged human DJ-1 (HEK293-DJ-1 cells), or with the corresponding empty vector (HEK293-neo cells). The UV-induced activation of endogenous JNK1, which was apparent in the control HEK293-neo cells, was abolished in the HEK293-DJ-1 cells (Figure 1b, Supplementary Figure 1B). To investigate whether the expression and modification of $\mathrm{DJ}-1$ is altered in UVexposed cells, we performed two dimensional gel electrophoresis experiment. Previous reports have described two main isoforms at $\mathrm{pl}=5.8$ and $6.2^{15-17}$ Samples were extracted from cells transfected with Flagtagged wild-type DJ-1, from either untreated cells or cells exposed to UV. We found that the immunoreactivity in the low-pl region of UV-treated cells (Figure 1c). The role of DJ-1 in the JNK1 signaling pathway was further evaluated by the knockdown of DJ-1 and L166P mutant expression using short interference DJ-1 (Supplementary Figures $3 A$ and $B$ ). Unlike what was observed in the control short interference plasmid-transfected cells, the cells transfected with short interference DJ-1 harbored low levels of DJ-1 (Figure 1d). The inhibition of endogenous JNK1 activity was restored in accordance with the coexpression of short interference DJ-1 in the HEK293-DJ-1 cells (Figure 1d, Supplementary Figure 1C). Figure 1e also indicates that endogenous JNK1 enzyme activity, which was stimulated by UV, was promoted through the downregulation of DJ-1 expression (Supplementary Figure 1D). These results indicate that the level of DJ-1 expression results in the inhibition of the JNK1 signaling pathway.

DJ-1 inhibits upstream and downstream components of JNK1. We then attempted to determine whether DJ-1 influences signaling upstream of JNK1, including the SEK1 and MEKK1 pathway. ${ }^{30,31}$ As UV was found to markedly
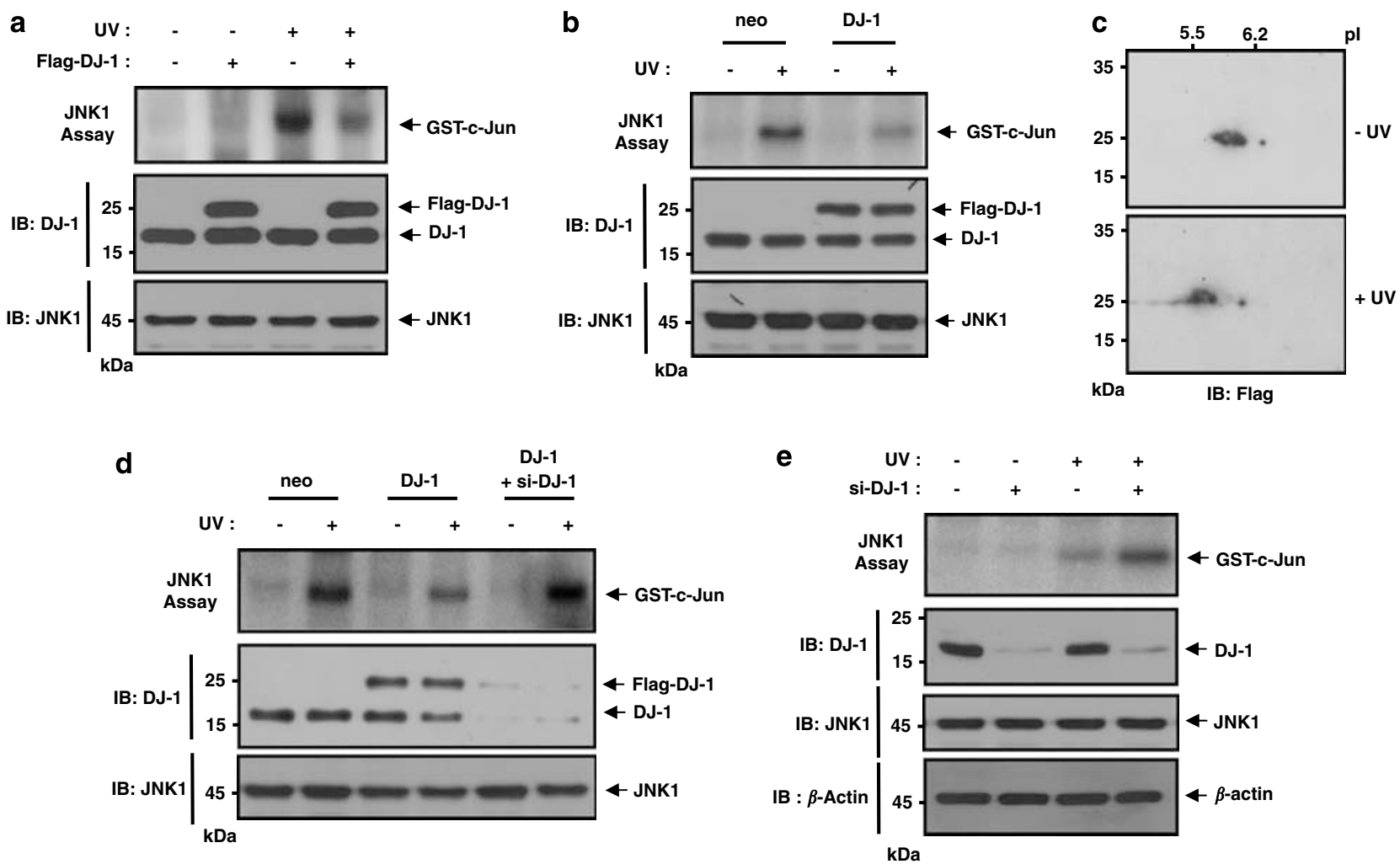

Figure 1 DJ-1 suppresses oxidative stress-induced JNK1 activation. (a) HEK293 cells were transiently transfected with plasmids expressing pcDNA3-HA-JNK1 or pcDNA3-Flag-DJ-1 as indicated. After $48 \mathrm{~h}$ of transfection, the cells were irradiated with UV light $\left(60 \mathrm{~J} / \mathrm{m}^{2}\right)$, incubated for an additional $1 \mathrm{~h}$ at $37^{\circ} \mathrm{C}$, and assayed for $\mathrm{JNK} 1$ activity through immunocomplex kinase assays. (b) HEK293-neo or HEK293-DJ-1 cells were exposed to UV light $\left(60 \mathrm{~J} / \mathrm{m}^{2}\right)$, incubated for an additional $1 \mathrm{~h}$ at $37^{\circ} \mathrm{C}$, and assayed for JNK1 activity through an immunocomplex kinase assay. (c) HEK293 cells were transiently transfected with plasmids expressing pcDNA3-Flag-DJ-1. After 48 h of transfection, the cells were irradiated with UV light $\left(60 \mathrm{~J} / \mathrm{m}^{2}\right)$, incubated for an additional $1 \mathrm{~h}$ at $37^{\circ} \mathrm{C}$. Cell lysates were subjected to two-dimensional gel electrophoresis followed by immunoblotting with anti-Flag antibody. (d) HEK293-neo or HEK293-DJ-1 cells were transfected with siRNA targeting DJ-1 or control siRNA. After 48h of transfection, the cells were irradiated with UV light $\left(60 \mathrm{~J} / \mathrm{m}^{2}\right)$, incubated for an additional $1 \mathrm{~h}$ at $37^{\circ} \mathrm{C}$, and assayed for JNK1 activity through an immunocomplex kinase assay. (e) HEK293 cells were transfected with siRNA targeting DJ-1 (pSUPER-siDJ-1) or control siRNA (pSUPER-siCon). After $48 \mathrm{~h}$ of transfection, the cells were irradiated with UV light $\left(60 \mathrm{~J} / \mathrm{m}^{2}\right)$, incubated for an additional $1 \mathrm{~h}$ at $37^{\circ} \mathrm{C}$, and assayed for $\mathrm{JNK} 1$ activity through an immunocomplex kinase assay. Cell lysates were immunoblotted with anti-JNK and anti-DJ-1 monoclonal antibodies. $\beta$-actin expression was analyzed by immunoblot using an anti- $\beta$-actin monoclonal antibody as a loading control. Immunocomplex JNK1 kinase assays were conducted using GST-c-Jun as the substrate. IB, immunoblot 
stimulate the activities of ectopically-expressed SEK1 (data not shown) and MEKK1 (data not shown) in the HEK293 cells, these effects were greatly reduced in DJ-1 transfected HEK293 cells (data not shown). We then determined that UV-induced endogenous SEK1 and MEKK1 activity in HEK293-DJ-1 and HEK293-neo cells. The UV-induced stimulation of endogenous SEK1 (Figure 2a, Supplementary Figure 2A) and MEKK1 (Figure 2b, Supplementary Figure 2B) activities were reduced remarkably in HEK293-DJ-1 cells, in comparison with HEK293-neo control cells. These data showed that DJ-1 overexpression also blocked UV-induced SEK1 and MEKK1 activity.

In the previous reports, it has been suggested that DJ-1 eliminated hydrogen peroxide in vitro by oxidizing itself. ${ }^{19} \mathrm{UV}$ also increases the quantity of intracellular ROS, which is critical with regard to the activation of JNK1 signaling. ${ }^{32}$ Therefore, we evaluated the role of DJ-1 in the ROSindependent activation of JNK1 using a constitutive active mutant of MEKK1 ( $\triangle \mathrm{MEKK1)}$ (Supplementary Figure 4). Surprisingly, DJ-1 was found to suppress the JNK1 (Figure 2c, Supplementary Figure 2C) and SEK1 (Figure 2d, Supplementary Figure 2D) activity stimulated by $\triangle \mathrm{MEKK} 1$ in the HEK293 cells. These results indicated that, at least in part, the suppression of the JNK1 signaling pathway by DJ-1 is not connected to ROS scavengers. We then assessed $\triangle \mathrm{MEKK} 1$ autophosphorylation activities in the HEK293 cells. DJ-1 overexpression prevents the autophosphorylation of $\triangle \mathrm{MEKK1}$ (Figure 2e). The inhibition of $\triangle \mathrm{MEKK1}$ enzyme activity by DJ-1 was restored according to the coexpression of short interference DJ-1 in HEK293 cells (Figure 2f, Supplementary Figure $2 \mathrm{E}$ ). Figure $2 \mathrm{~g}$ also indicates that $\triangle \mathrm{MEKK} 1$ enzyme activity was promoted through the downregulation of DJ-1 expression. Furthermore, immune complex kinase assay with endogenous MEKK1 revealed that UV treatment increased the kinase activity of endogenous MEKK1 in cells expressing short interference control vector, and that these effects were enhanced in cells expressing short interference DJ-1 (Figure $2 \mathrm{~h}$ ). Thus, our data indicate that MEKK1 may be the principal target protein of DJ-1 in the MEKK1-SEK1-JNK1 signaling cascade through a certain mechanism.

The transcription factor c-Jun is a physiological target of JNK1. ${ }^{33}$ Thus, we attempted to determine whether DJ-1 influences the JNK1 signaling-dependent increase in the transactivation activity of C-Jun, through a luciferase reporter gene assay. UV caused an increase in c-Jun-dependent luciferase activity and c-Jun Phosphorylation, and this effect was inhibited by DJ-1 (Figure 3a). In HEK293 cells, over- expressed $\triangle \mathrm{MEKK} 1$ functions as a constitutive active form of the enzyme and enhances c-Jun-dependent luciferase activity. The $\triangle \mathrm{MEKK} 1$ induced a transcription-stimulating activity of c-Jun, which was blocked by DJ-1 (Figure 3b). Unlike the control short interference plasmid-transfected cells, the short interference DJ-1-transfected cells evidenced an elevated basal level of $\mathrm{c}$-Jun (Figure $3 \mathrm{c}$ ) and $\triangle \mathrm{MEKK1-}$ dependent $c$-Jun transactivation activity (Figure $3 \mathrm{c}$ ). These results indicate that $\mathrm{DJ}-1$ inhibits the MEKK1-dependent transactivation activity of c-Jun.

DJ-1 inhibits MEKK1 activity, but not SEK1 and JNK1 activities in vitro. The effect of DJ-1 on MEKK1 activity in vitro was assessed to determine whether DJ-1 directly targets MEKK1. Compared to endogenous and ectopic expressed DJ-1, similar level of purified DJ-1 proteins were used in this experiment (Supplementary Figure $3 C$ ). An active MEKK1 was acquired through the immunoprecipitation of UV-exposed HEK293 cells using anti-MEKK1 antibody. In the in vitro kinase assay, the pretreatment of active MEKK1 with purified DJ-1 protein resulted in an inhibition of MEKK1 activity (Figure 4a). By way of comparison, DJ-1 pretreatment had little effect on the enzymatic activity of either SEK1 (Figure 4b) or JNK1 (Figure 4c) in vitro. DJ-1 also inhibited the enzymatic activity of $\triangle \mathrm{MEKK1}$ (Figure $4 \mathrm{~d}$ ). Furthermore, pretreatment with DJ-1 did not directly influence the activities of any other MAP3Ks in vitro, including MLK3 and TAK1 (Figure 4e). Additional experiment shows that GST and BSA did not suppress the enzyme activity of MEKK1 (Figure 4f). Thus, our data indicate that MEKK1 was the principal target protein of DJ1 in the MEKK1-SEK1-JNK1 signaling cascade. DJ-1 was not phosphorylated by MEKK1 (data not shown).

DJ-1 interacts physically with MEKK1 in intact cells. We then evaluated the physical interactions occurring between DJ-1 and MEKK1. Coimmunoprecipitation analysis revealed that MEKK1 did associate physically with DJ-1 (Figure 5a). We also attempted to characterize the interaction occurring between MEKK1 and the pathogenic L166P mutant form of DJ-1. We transfected the cells with an increased quantity of the L166P encoding vector to attain an expression level comparable to that of the wild-type DJ-1. Despite the similar amounts of wild-type and DJ-1 (L166P), the interaction between MEKK1 and the mutant was much weaker than with the wild-type DJ-1 (Figure 5a). This result implies that the impaired binding of DJ-1(L166P) to MEKK1 is attributable not to its lower expression level, but rather to a conformational

\footnotetext{
Figure 2 DJ-1 inhibits SEK1 and MEKK1 activities. (a, b) HEK293-neo or HEK293-DJ-1 cells were exposed to UV light $\left(60 \mathrm{~J} / \mathrm{m}^{2}\right)$, incubated for an additional $1 \mathrm{~h}$ at $37^{\circ} \mathrm{C}$, and assayed for SEK1 or MEKK1 activity through immunocomplex kinase assays using GST-JNK1(K55R) or GST-SEK1(K129R) as the substrates, respectively. (c) HEK293 cells were transiently transfected with plasmids expressing pcDNA3-Flag- $A$ MEKK1, pcDNA3-HA-JNK1 or pcDNA3-His-DJ-1 as indicated. (d) HEK293 cells were transiently transfected with plasmids expressing pcDNA3-Flag-4MEKK1, pEBG-GST-SEK1 or pcDNA3-His-DJ-1 as indicated. (e) HEK293 cells were transiently transfected with plasmids expressing pcDNA3-Flag- 4 MEKK1 or pcDNA3-His-DJ-1 as indicated. (f) HEK293 cells were transiently transfected with plasmids expressing pcDNA3-Flag$\triangle$ MEKK1, pcDNA3-His-DJ-1, pSUPER-siCon or pSUPER-siDJ-1 as indicated. After $48 \mathrm{~h}$ of transfection, the cells were assayed for kinase activity through immunocomplex kinase assays. (g) HEK293 cells were transiently transfected with plasmids expressing pcDNA3-Flag- $\triangle$ MEKK1, pSUPER-siCon or pSUPER-siDJ-1 as indicated. After 48 $\mathrm{h}$ of transfection, the cells were assayed for kinase activity through immunocomplex kinase assays. (h) HEK293 cells were transiently transfected with plasmids expressing pSUPER-siCon or pSUPER-siDJ-1 as indicated. After $48 \mathrm{~h}$ of transfection, the cells were assayed for kinase activity through immunocomplex kinase assays. (a-h) Cell lysates were immunoblotted with anti-SEK1, anti-MEKK1, anti-Flag, anti-His, anti-HA, and anti-DJ-1 antibodies. IB, immunoblot
} 
change imposed by the mutation. We also detected a direct interaction occurring between ectopically expressed wild-type DJ-1 and endogenous MEKK1, whereas the L166P mutant of

a
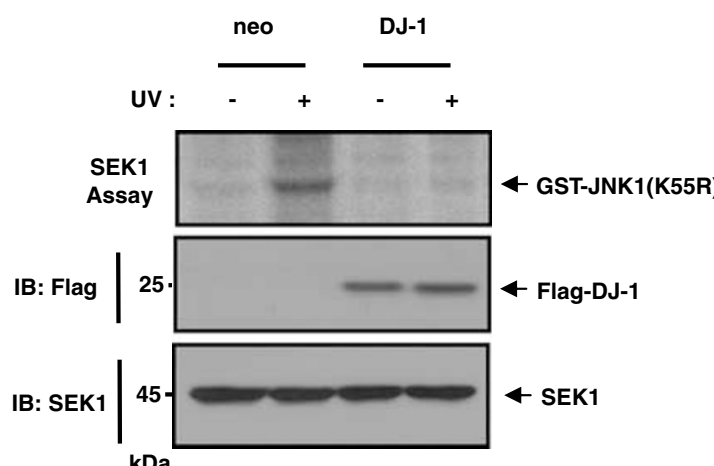

C Flag- $\triangle$ MEKK1: - $\quad-\quad++$

HA-JNK1: ++++

His-DJ-1: $\quad-\quad+\quad+$
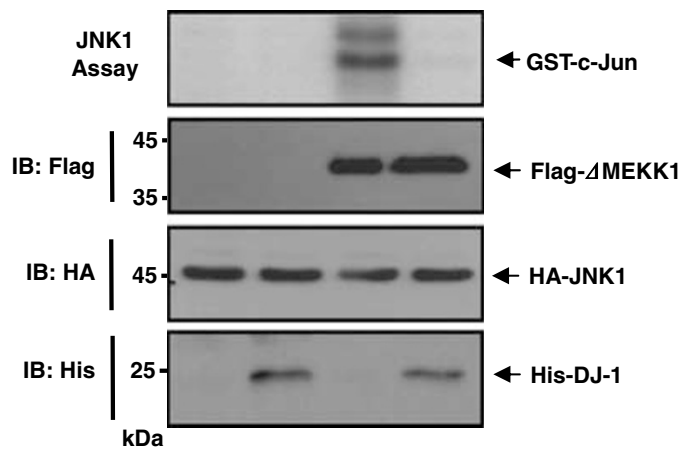

e

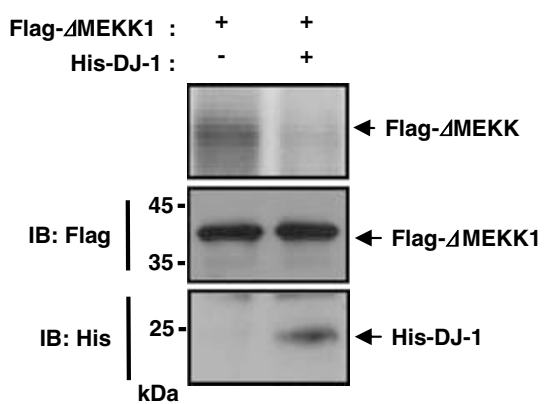

g

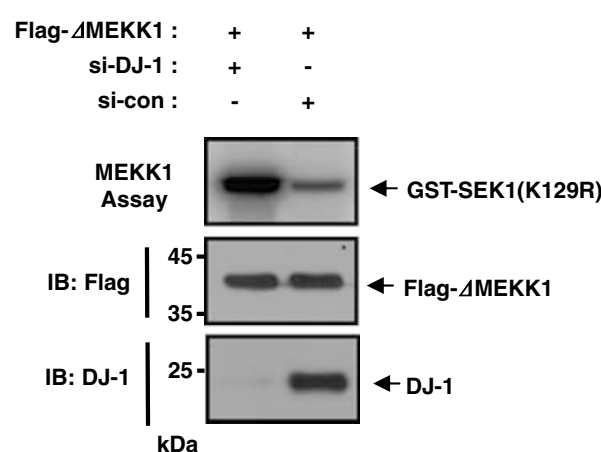

DJ-1 was not detected in an identical immunocomplex with endogenous MEKK1 using HEK293-neo, HEK293-DJ-1, and HEK293-L166P stable cell lines (Figure 5b). We also

b
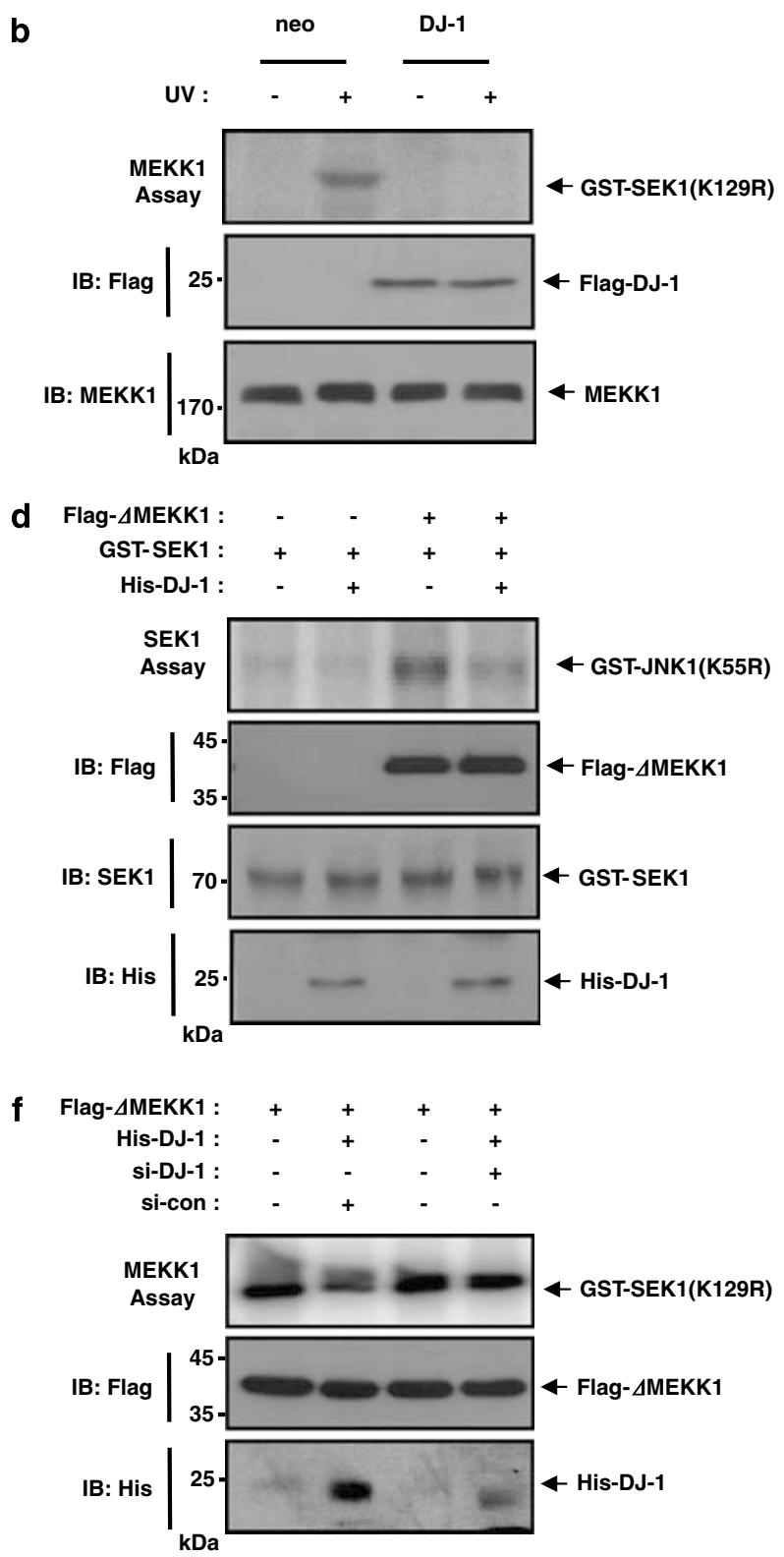

h
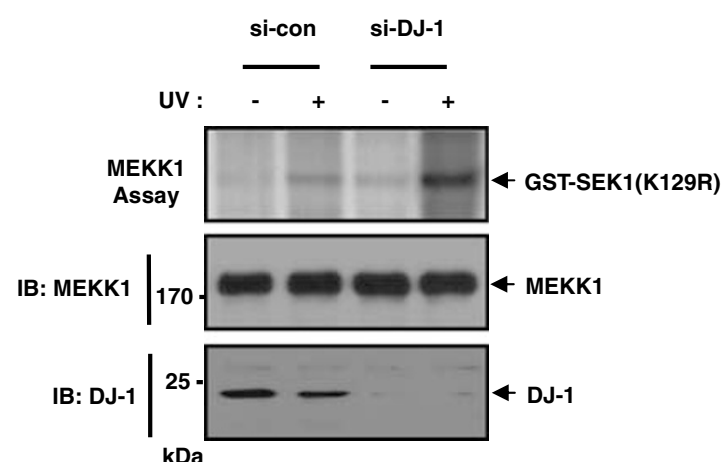
a
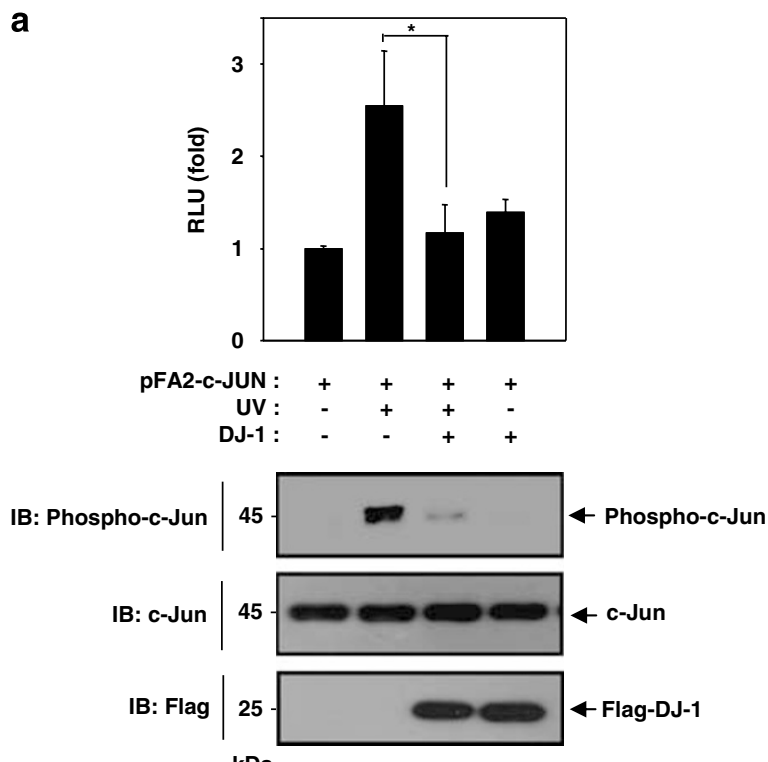

b

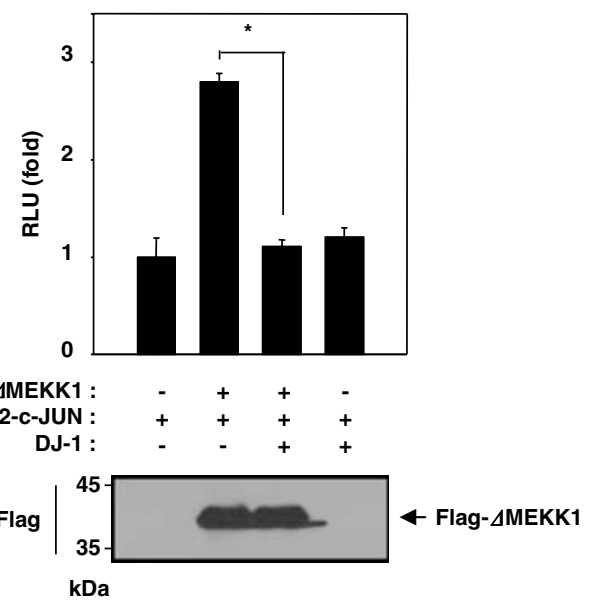

c

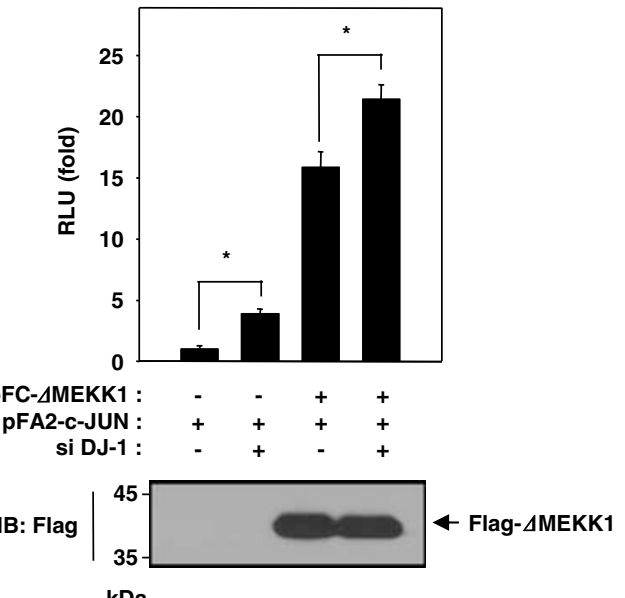

Figure 3 DJ-1 inhibits transactivating activity of c-Jun stimulated by the JNK pathway. (a) HEK293 cells were transiently transfected with a luciferase reporter plasmid pFRLuc, pFA2-c-Jun, or pcDNA3-flag-DJ-1 along with pCMV- $\beta$-galactosidase as indicated. After $44 \mathrm{~h}$, the transfectants were exposed to UV light $\left(60 \mathrm{~J} / \mathrm{m}^{2}\right)$, and incubated for an additional $4 \mathrm{~h}$ at $37^{\circ} \mathrm{C}$. Cell lysates were immunoblotted with anti-phopho-c-Jun, anti-c-Jun, and anti-Flag antibodies. (b, c) HEK293 cells were transiently transfected with the luciferase reporter plasmids pFR-Luc, pFA2-c-Jun, pFC- $\Delta$ MEKK1, pcDNA3-flag-DJ-1, or pSUPER-siDJ-1 along with pCMV- $\beta$-galactosidase as indicated. (a-c) After $48 \mathrm{~h}$, the transfectants were lysed and assayed for luciferase activity. The luciferase activity of each sample was normalized using the $\beta$-galactosidase activity measured in the same sample. The data are expressed as the means \pm S.D. of triplicates from one of two independent experiments. All of these results are representative of at least three independent experiments. *ANOVA, $P<0.001$. Cell lysates were immunoblotted with anti-Flag antibody. IB, immunoblot

examined whether endogenous DJ-1 and MEKK1 could interact in intact cells. Immunoblot analysis using anti-DJ-1 antibody of the MEKK1 immunoprecipitates indicated that the physical association of two endogenous DJ-1 and MEKK1 in intact cells (Figure 5c). Immunoblot analysis using anti-DJ-1 antibody of the MEKK1 immunoprecipitates indicated that UV treatment suppresses the physical association of two endogenous DJ-1 and MEKK1 in HEK293 cells. However, exposure of the cells to UV could not prevent the physical interaction between ectopic expressed DJ-1 and endogenous MEKK1 (Figure 5c). Furthermore, we were unable to detect any association between the DJ-1 or L166P mutant and JNK1, or SEK1 by subsequent experiments (data not shown).

Next, we examined the effect of DJ-1 on the physical interaction between two MEKK1 and SEK1 proteins by coimmunoprecipitation. Coimmunoprecipitation assay with endogenous MEKK1 and SEK1 revealed that the binding in cells expressing short interference control vector, and that these effects were enhanced in cells expressing short interference DJ-1 (Figure 5d). Thus, our data indicate that MEKK1 may be the principal target protein of DJ-1 in the MEKK1-SEK1-JNK1 signaling cascade through disruption of binding with downstream substrate.

We then attempted to ascertain which of the domains might be involved in the interaction between MEKK1 and DJ-1. In vitro binding analysis with GST-fused MEKK1 deletion mutants showed that the kinase domain of MEKK1 interacted with DJ-1 (Figure 5e). Subsequent experiments revealed that the carboxyl-terminal (amino acids 165-189) of DJ-1 prevented MEKK1 kinase activity (Figure $5 f$ ). The findings of this study indicated that DJ-1 inhibits the activation of MEKK1 without its quenching ability against reactive oxygen species, but that physical interaction is crucial for the function of DJ-1. 
a

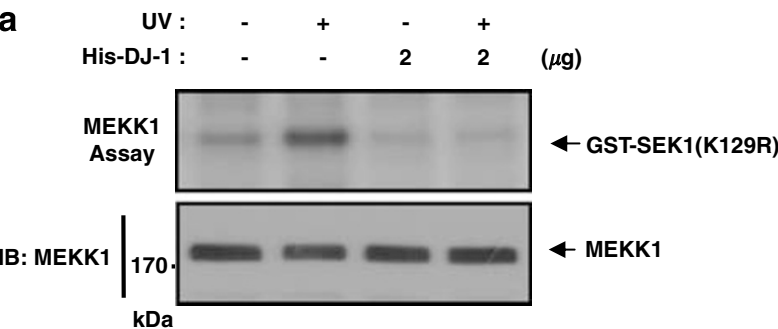

b

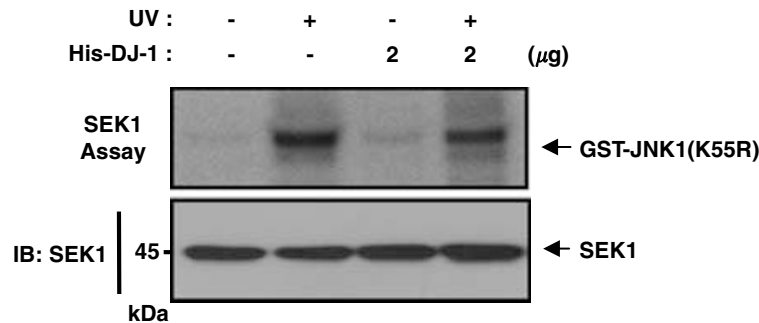

c

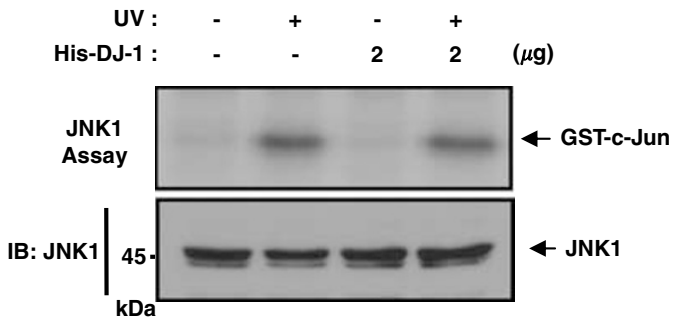

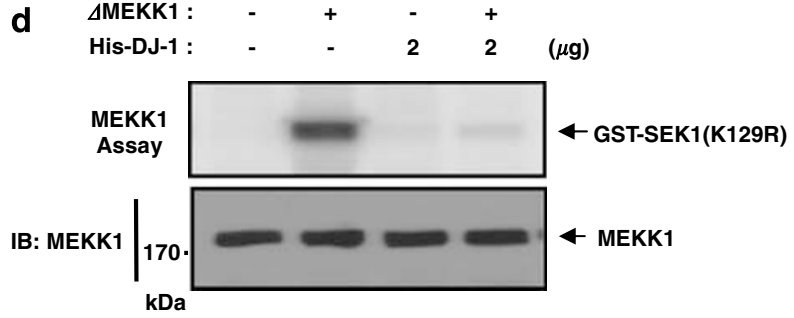

e

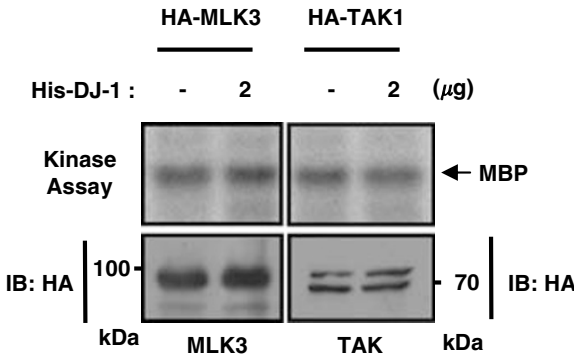

f

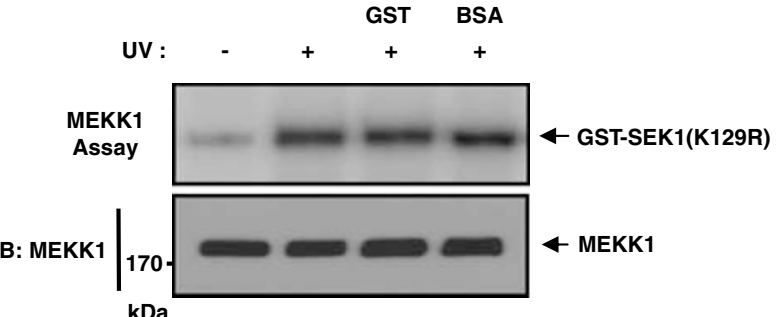

Figure 4 DJ-1 inhibits MEKK1 activity, but not SEK1 and JNK1 activities in vitro. (a-c) HEK293 cells were irradiated with UV light $\left(60 \mathrm{~J} / \mathrm{m}^{2}\right)$, incubated for an additional $1 \mathrm{~h}$ at $37^{\circ} \mathrm{C}$, and then subjected to immunoprecipitation using anti-JNK1, anti-SEK1, or anti-MEKK1 antibody as indicated. (d) DJ-1 inhibits the constitutive active mutant of MEKK1. HEK293 cells were transiently transfected with pcDNA3-flag-4MEKK1 and subjected to immunoprecipitation using anti-Flag antibody as indicated. (e) DJ-1 has no effect on MLK3 and TAK1. HEK293 cells were transiently transfected with pcDNA3-HA-MLK3 or pcDNA3-HA-TAK1, and then subjected to immunoprecipitation using antiFlag antibody as indicated. (a-e) The immunopellets were incubated with purified DJ-1 protein in $50 \mu \mathrm{l}$ of HEPES buffer at a pH of 7.4 for $1 \mathrm{~h}$ at room temperature, washed twice with HEPES buffer, then assayed for JNK1, SEK1, or MEKK1 activity using GST-C-Jun, GST-JNK1(K55R), or GST-SEK1(K129R) as the substrates, respectively. Immunocomplex kinase assays for MLK3 and TAK were conducted using myelin basic protein (MBP) as a universal substrate. (f) HEK293 cells were irradiated with UV light $\left(60 \mathrm{~J} / \mathrm{m}^{2}\right)$, incubated for an additional $1 \mathrm{~h}$ at $37^{\circ} \mathrm{C}$, and then subjected to immunoprecipitation using anti-MEKK1 antibody as indicated. The immunopellets were incubated with purified $2 \mu \mathrm{g}$ of GST or BSA proteins, then assayed for MEKK1 activity using GST-SEK1(K129R) as a substrate. Cell lysates were immunoblotted with anti-MEKK1, antiSEK1, anti-JNK1, and anti-HA antibodies. IB, immunoblot

DJ-1 sequesters MEKK1 in the cytoplasm and L166P mutant enhances the nuclear accumulation of MEKK1. In an attempt to determine the role of the pathogenic L166P mutant form of DJ-1 in the JNK1 signaling pathway, we conducted an endogenous JNK1 kinase assay using HEK293-neo and L166P mutant stableexpressing cells (HEK293-L166P). The UV-induced activation of endogenous JNK1, SEK1, and MEKK1 apparent in the control HEK293-neo cells was enhanced to a greater extent in the HEK293-L166P cells (Figure 6a). Furthermore, we observed that the DJ-1 mutants (C46A, C53A) induced significant MEKK1 activation, whereas C106A was ineffective in this regard (Figure 6b). MEKK1 is localized principally to the cytoplasm in unstimulated cells. During signal propagation, MEKK1 is translocated to the nucleus and thereby regulate gene expression. ${ }^{34,35}$ Wildtype DJ-1 is distributed throughout both the cytoplasm and nucleus. The L166P mutant has been reported to be localized, in part, in both the mitochondria and nucleus. ${ }^{5}$ We determined that UV stress induces the nuclear accumulation of MEKK1 using confocal study (Figure 6c) and cell fractionation (Supplementary Figure 5, Figures $6 \mathrm{e}$ and f). To characterize the effects of the wild-type DJ-1 and L166P mutant on the translocation of MEKK1 from the cytoplasm to the nucleus, the cells were cotransfected with HA-MEKK1, Flag-DJ-1, and Flag-DJ-1 (L166P). The expression of wild-type DJ-1 substantially blocked the UVinduced translocation of MEKK1 into the nucleus (Figures 6c and e). The pathogenic mutant of DJ-1 facilitates the nuclear translocation of MEKK1 (Figures $6 \mathrm{c}$ and d). Nuclear localization of MEKK1 in the presence of L166P mutant was corroborated through the immunoblotting of extracts of the nuclear fractions (Figures $6 \mathrm{e}$ and $\mathrm{f}$ ). The results of this experiment demonstrate the protective role of $\mathrm{DJ}-1$ and also show that the stimulatory role of the pathogenic mutant of DJ-1 in the JNK1 signaling pathway might be associated with the regulation of MEKK1 subcellular localization.

Different role of wild-type and L166P mutant DJ-1 against UV-induced cell death. Next, we evaluated the 
a

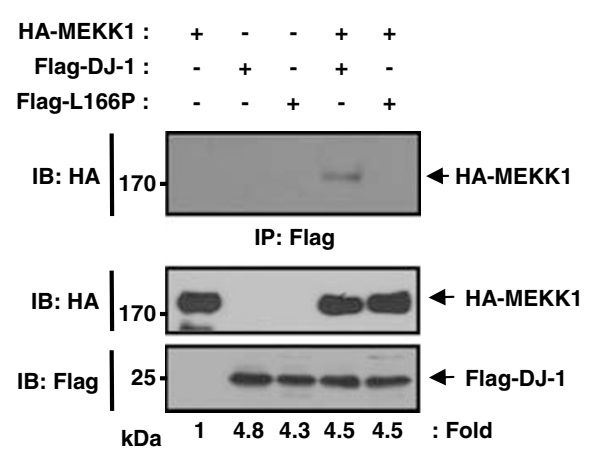

C

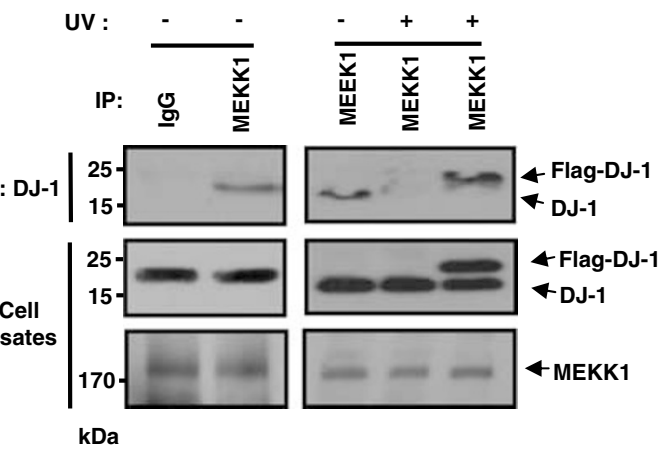

e
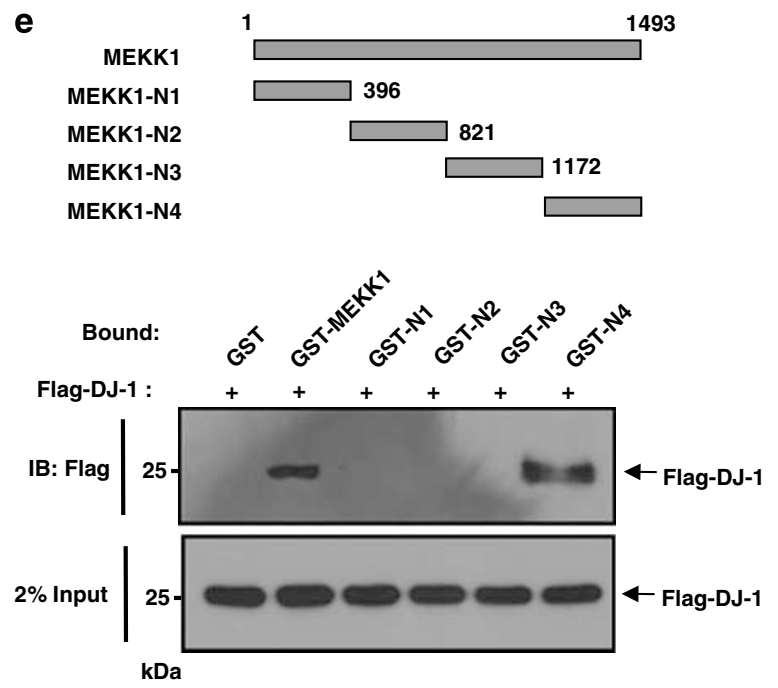

b

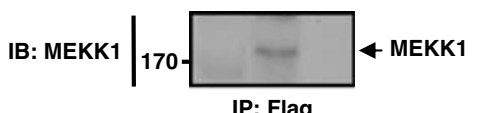

$$
\text { IP: Flag }
$$

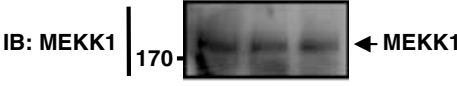

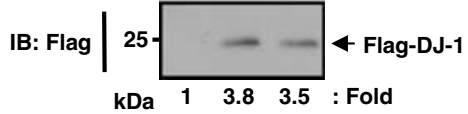

d
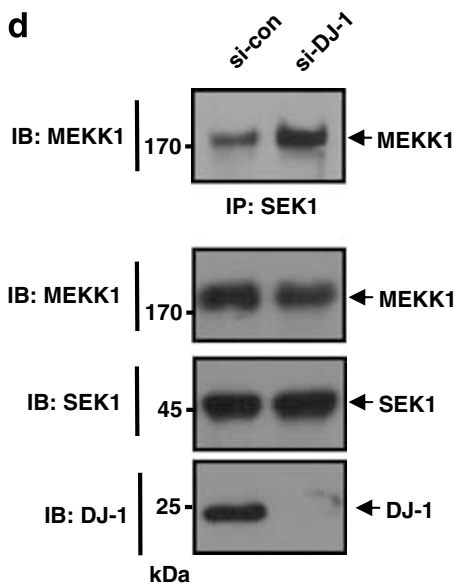

f
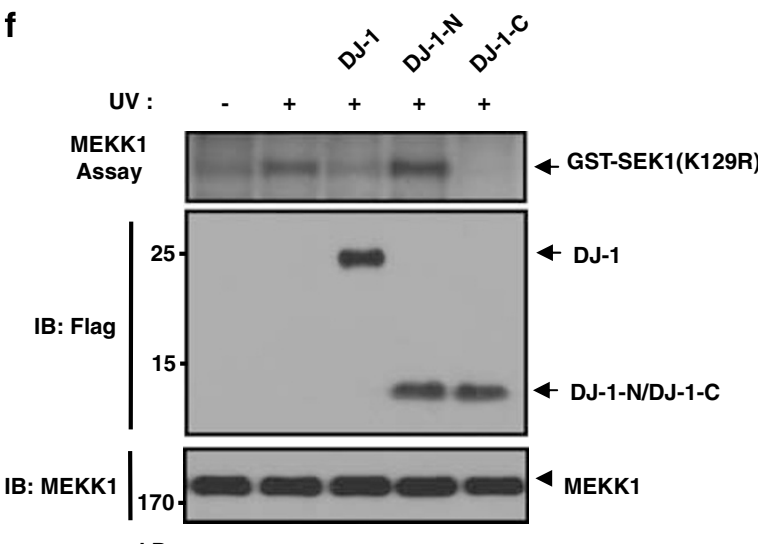

kDa

Figure 5 DJ-1 interacts physically with MEKK1 in intact cells. (a) HEK293 cells were transiently transfected with $1 \mu \mathrm{g}$ of pcDNA3-HA-MEKK1, $1 \mu \mathrm{g}$ of pcDNA-Flag-DJ-1, or $3 \mu \mathrm{g}$ of pcDNA-Flag-DJ-1(L166P) to attain equivalent expression levels. Cells were lysed and subjected to immunoprecipitation with anti-Flag antibody as indicated. Immunoprecipitates were immunoblotted with anti-HA antibody. The expression of MEKK1, wild-type DJ-1, or the L166P mutant DJ-1 was analyzed through immunoblot using anti-HA or anti-Flag monoclonal antibody, respectively. (b) HEK293-neo, HEK293-DJ-1, and HEK293-DJ-1(L166P) cells were lysed and subjected to immunoprecipitation with anti-Flag antibody as indicated. Immunoprecipitates were immunoblotted with anti-MEKK1 antibody. Cell lysates were immunoblotted with anti-Flag and anti-MEKK1 antibodies as a control. (c) HEK293 cells were transiently transfected with pcDNA-Flag-DJ-1 as indicated. After $48 \mathrm{~h}$ of transfection, the cells were irradiated with UV light (60 J/ $\mathrm{m}^{2}$ ), further incubated for $1 \mathrm{~h}$ at $37^{\circ} \mathrm{C}$. HEK293 cells were lysed and subjected to immunoprecipitation with anti-MEKK1 antibodies as indicated. Immunoprecipitates were immunoblotted with anti-DJ-1 antibody. Cell lysates were immunoblotted with anti-DJ-1 and anti-MEKK1 antibodies as a control. (d) HEK293 cells were transiently transfected with pSUPER-siCon or pSUPER-siDJ-1 as indicated. After $48 \mathrm{~h}$ of transfection, the cells were irradiated with UV light $\left(60 \mathrm{~J} / \mathrm{m}^{2}\right)$, further incubated for $1 \mathrm{~h}$ at $37^{\circ} \mathrm{C}$. HEK293 cells were lysed and subjected to immunoprecipitation with anti-SEK1 antibodies as indicated. Immunoprecipitates were immunoblotted with anti-MEKK1 antibody. Cell lysates were immunoblotted with anti-DJ-1, anti-SEK1, and anti-MEKK1 antibodies as a control. (e) HEK293 cells were transfected with pcDNA-Flag-DJ-1 and then the cell extracts were added to the recombinant GST control, GST-MEKK1 or GST-MEKK1-N1 N4 deletion mutants proteins immobilized onto GSH-agarose beads. Bound proteins were extensively washed, eluted, separated by SDS-PAGE and analyzed through immunoblotting using anti-Flag monoclonal antibody. (f) HEK293 cells were transiently transfected with pcDNA-Flag-DJ-1, pcDNA-Flag-DJ-1-N, or pcDNA-Flag-DJ-1-C as indicated. After $48 \mathrm{~h}$ of transfection, the cells were irradiated with UV light $\left(60 \mathrm{~J} / \mathrm{m}^{2}\right)$, further incubated for $1 \mathrm{~h}$ at $37^{\circ} \mathrm{C}$, and assayed for MEKK1 activity through immunocomplex kinase assay. Cell lysates were immunoblotted with anti-DJ-1 and anti-MEKK1 antibodies as a control. IB, immunoblot 
a

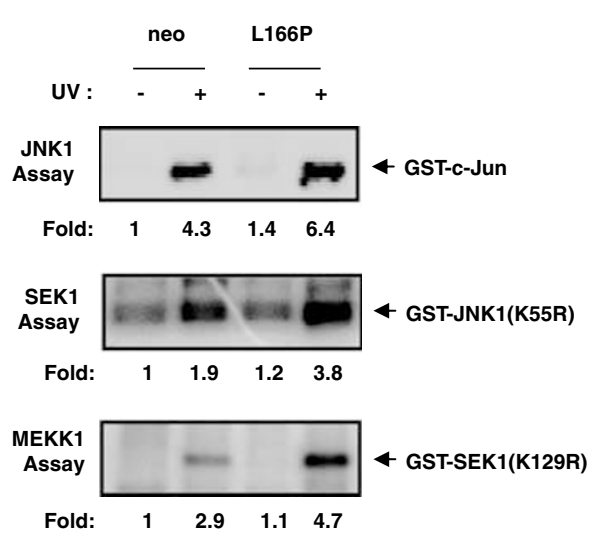

d

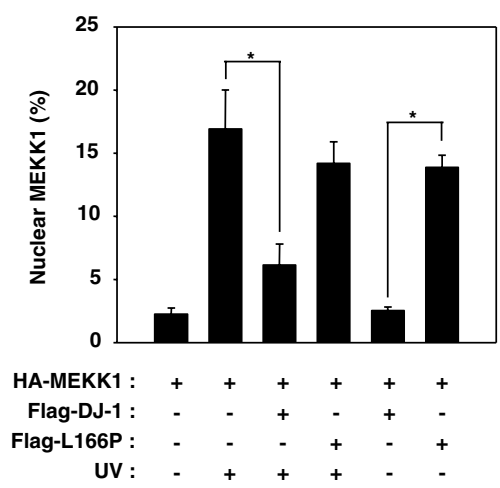

e
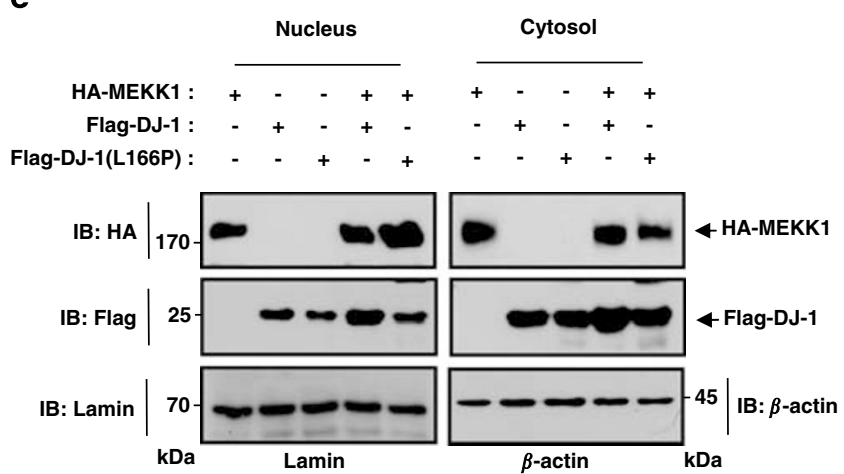

b

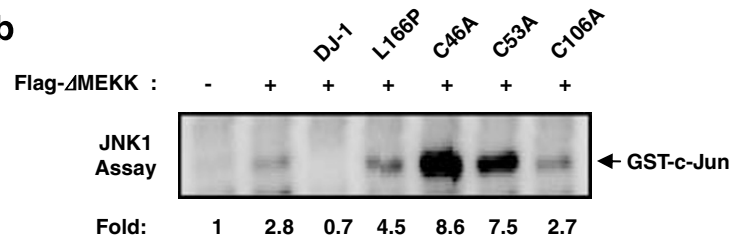

c
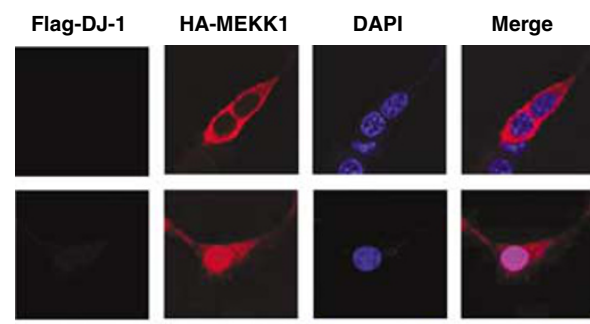

HA-MEKK1
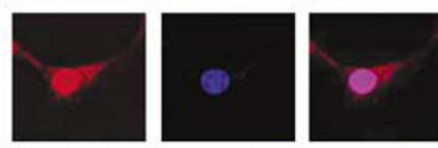

HA-MEKK1

UV
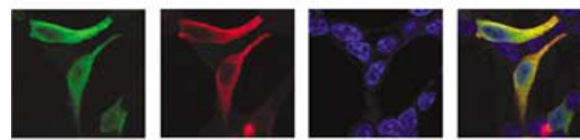

HA-MEKK1

Flag-DJ-1

UV
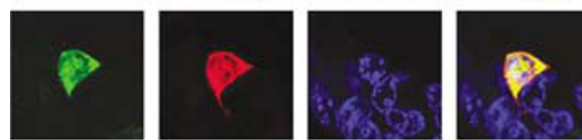

HA-MEKK1

Flag-L166P

UV
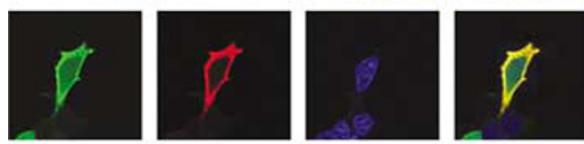

HA-MEKK1

Flag-DJ-1
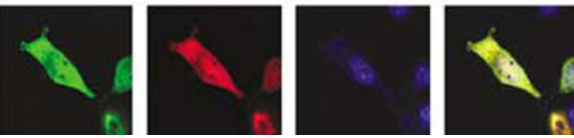

HA-MEKK1

Flag-L166P

f
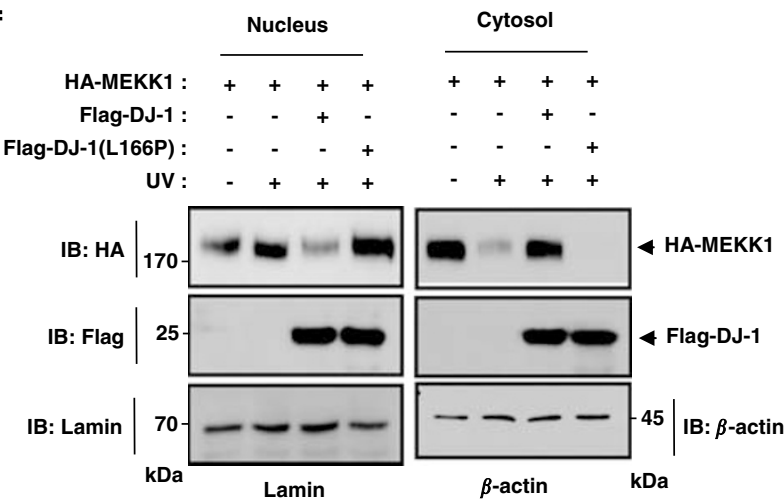

Figure 6 DJ-1 sequesters MEKK1 in the cytoplasm and the L166P mutant enhances the nuclear accumulation of MEKK1. (a) The pathogenic L166P mutant facilitates the activation of the JNK1 signaling pathway. HEK293-neo or HEK293-L166P cells were irradiated with UV light $\left(60 \mathrm{~J} / \mathrm{m}^{2}\right)$, incubated for an additional $1 \mathrm{~h}$ at $37^{\circ} \mathrm{C}$, and assayed for JNK1, SEK1, or MEKK1 activity through immunocomplex kinase assay. (b) HEK293 cells were transfected with pcDNA3-Flag- 4 MEKK1, pcDNA3-V5/His-DJ, pcDNA3-V5/HisDJ-1 (L166P), pcDNA3-V5/His-DJ-1 (C46A), pcDNA3-V5/His-DJ-1 (C53A), and pcDNA3-V5/His-DJ-1 (C106A). After 48 h of transfection, the cells were assayed for kinase activity through immunocomplex kinase assays. (c) HEK293 cells were transfected with pcDNA3-HA-MEKK1, pcDNA-Flag-DJ-1, or pcDNA-Flag-DJ-1 (L166P). After 48 h, the cells were exposed to UV light $\left(60 \mathrm{~J} / \mathrm{m}^{2}\right)$, and incubated for an additional $1 \mathrm{~h}$ at $37^{\circ} \mathrm{C}$ as indicated. MEKK1 and DJ-1 were stained with rhodamine (red) and fluorescein (green). (d) The cells in which MEKK1 was detected in the nucleus were counted in 10 randomly selected fields among the cotransfected cells. Data are expressed as the means \pm S.D. from one of three independent experiments. *ANOVA, $P<0.001$. (e, f) HEK293 cells were transfected with HA-MEKK1, Flag-DJ-1, Flag-DJ-1 (L166P) as indicated. (e) After $48 \mathrm{~h}$, cells were fractionated into cytosolic and nuclear fractions. (f) After $48 \mathrm{~h}$, cells were exposed to UV light $\left(60 \mathrm{~J} / \mathrm{m}^{2}\right)$, and incubated for an additional $45 \mathrm{~min}$ at $37^{\circ} \mathrm{C}$. (e, f) The cell lysates were also subjected to immunoblotting analysis with antibodies against HA and Flag. Lamin and $\beta$-actin were used as nuclear and cytoplasmic fraction marker. IB, immunoblot 

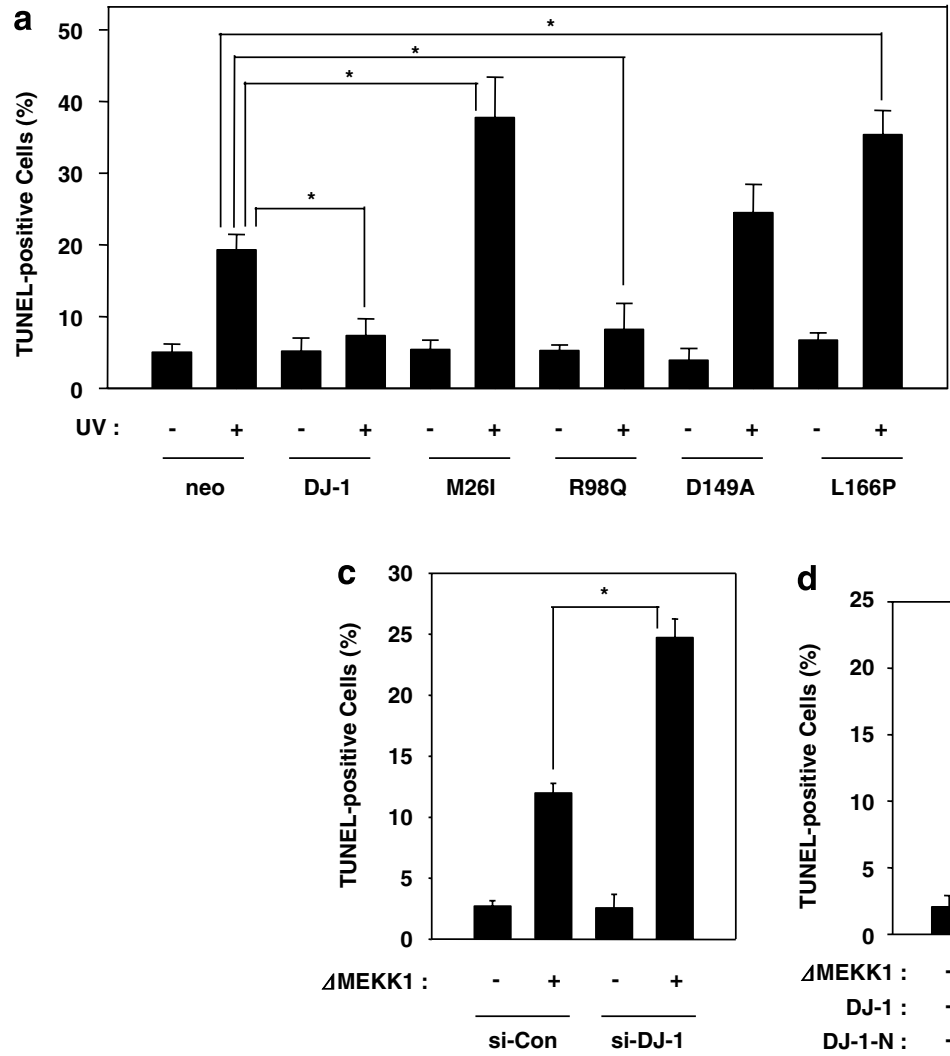

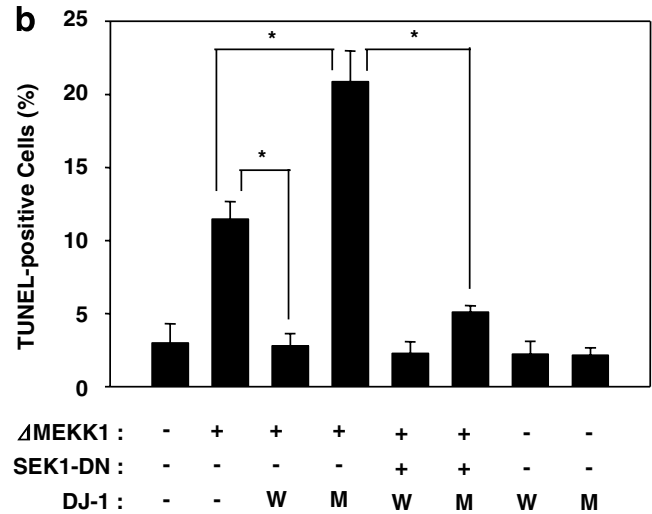

d

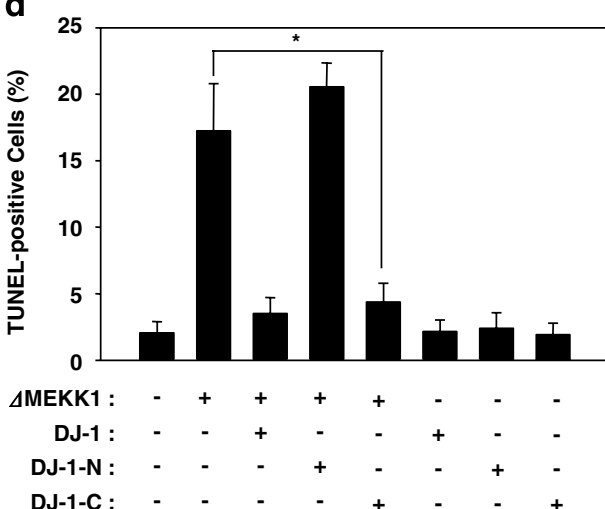

Figure 7 Different role of wild-type and L166P mutant DJ-1 against UV-induced cell death. (a) HEK293 cells were transiently transfected with pcDNA3-Flag-DJ-1, pcDNA3-Flag-DJ-1 (M26I), pcDNA3-Flag-DJ-1 (R98Q), pcDNA3-Flag-DJ-1 (D149A), and pcDNA3-Flag-DJ-1(L166P). (b) HEK293 cells were transiently transfected with pcDNA3-Flag-AMEKK1, pcDNA3-SEK1-DN, pcDNA3-Flag-DJ-1 or pcDNA3-Flag-DJ-1(L166P). (c) The HEK293 cells were transiently transfected with pcDNA3-Flag$\triangle$ MEKK1, pSUPER-Si-DJ-1, or pSUPER-siCon. (d) The HEK293 cells were transiently transfected with pcDNA3-Flag- $\triangle$ MEKK1, pcDNA-Flag-DJ-1, pcDNA-Flag-DJ1-N, or pcDNA-Flag-DJ1-C. (a-d) After $50 \mathrm{~h}$, the cells were analyzed for cell death using TUNEL staining. The transfected cells were fixed, permeabilized and incubated with terminal deoxynucleotidyl transferase and fluorescein-labeled dUTP. TUNEL-positive cells were examined with a fluorescence microscope. Data are expressed as the means \pm S.D. of triplicates from one of two independent experiments. All results were representative of at least three independent experiments. ${ }^{*}$ ANOVA, $P<0.001$

effects of DJ-1 on JNK1-dependent cell death. UV irradiation induced incremental apoptotic cell death in HEK293-neo cells, and this cell death might be repressed by wild-type DJ-1 and nonpathogenic R98Q mutant of DJ-1 (Figure 7a). The results of a recent report have demonstrated the loss of the antiapoptotic activities of DJ-1 mutants. ${ }^{19,21}$ In our cell death experiment, we determined that the pathogenic M26I, D149A and L166P mutant of DJ-1 facilitates UVinduced cell death (Figure 7a). We then assessed the effects of wild-type DJ-1 and the L166P mutant of DJ-1 on $\triangle \mathrm{MEKK1-}$ induced cell death. The overexpression of $\triangle \mathrm{MEKK} 1$, a constitutively active form of MEKK1, resulted in an increase in apoptotic cell death in HEK293 cells, and this apoptotic effect could be repressed by wild-type DJ-1 (Figure 7b). However, the expression of L166P mutant DJ1 in HEK293 cells was determined to be more sensitive to $\triangle \mathrm{MEKK} 1$-induced cell death than that was in wild-type DJ-1 expression, and this function was successfully suppressed by coexpression with the dominant negative form of SEK1 (Figure $7 \mathrm{~b}$ ). These data thus indicate that the pathogenic L166P mutant of DJ-1 was most sensitive to UV-induced apoptotic cell death, and this sensitivity may be dependent on the MEKK1-SEK1-JNK1 pathway. Furthermore, DJ-1 siRNA was found to enhance $\triangle \mathrm{MEKK} 1$-induced apoptotic cell death (Figure 7c). We then tested the effects of DJ-1 deletion mutants on $\triangle \mathrm{MEKK} 1$-induced cell death in HEK293 cells transiently transfected with plasmids expressing $\triangle \mathrm{MEKK} 1$ and the DJ-1 proteins. Our result shows that $\triangle$ MEKK1-dependent cell death was repressed by full-length DJ-1 or DJ-1-C, but not by DJ-1-N (Figure 7d). Taken together, these data strongly indicate that DJ-1, through binding to MEKK1, suppresses UV-induced apoptosis, and that the pathogenic L166P mutant of DJ-1 resulted in cell death.

\section{Discussion}

We have determined that DJ-1 physically interacts with MEKK1 and inhibits MEKK1 activation, resulting in the suppression of MEKK1-mediated cell death. DJ-1 is a potent inhibitor of the oxidative stress-induced cell death signaling pathway. These observations indicate that the inhibition of MEKK1 is an important mechanism by which DJ-1 operates as a negative regulator of the JNK1 signaling pathway. 
DJ-1 prevents the cell death triggered by a variety of apoptotic stimuli, including hydrogen peroxide, dopamine, UV irradiation, and MPP $+.^{19-21} \mathrm{DJ}-1$ expression was determined to be induced through oxidative stress. ${ }^{16-18}$ Thus far, DJ-1 has been implicated in the modulation of several signaling processes associated with the regulation of cell death. A recent report has demonstrated that the hydrogen peroxide-quenching ability of DJ-1 may not be sufficient to account for its overall cytoprotective functions. ${ }^{29}$ Our findings in this study represent compelling evidence that wild-type DJ-1 and the pathogenic L166P mutant of DJ-1 evidence identical hydrogen peroxide quenching abilities. However, wild-type and L166P mutant DJ-1 play different roles in the oxidative stress-induced activation of the JNK1 signaling pathway and cell death. Therefore, we can surmise that the hydrogen peroxide quenching ability of $\mathrm{DJ}-1$ is not sufficient to regulate oxidative stress-mediated JNK1 activation and cell death.

The Mouradian group has suggested that DJ-1 may interact with Daxx, sequestering it within the nucleus and preventing it from gaining access to the cytoplasm, thereby blocking Daxxmediated ASK1 activation. ${ }^{29}$ Several studies have proposed that dopaminergic neuronal death is increased through the activation of the JNK signaling pathway. ${ }^{36-39}$ These observations indicate that JNK may exert an important effect in the mediation of dopaminergic neuronal death, and that the blockage of JNK signaling through specific inhibitors may prevent or effectively retard the progression of $\mathrm{PD}$ and other neurodegenerative diseases. Our data now reveal a new mechanism: wild-type DJ-1 directly interacts with and thereby inhibits MEKK1 activation, thus resulting in the suppression of MEKK1-mediated cell death. Considering that MEKK1 is an MAP3K that participates in the JNK signaling cascade, the inhibition of MEKK1 activation by $\mathrm{DJ}-1$ may also be an important mechanism through which DJ-1 inhibits the JNK signaling pathway in the progression of PD.

Deletion and point mutations of DJ-1 have recently been implicated in the onset of familiar PD. In both the previous reports and in this study, the results of cell-death experiments have indicated that DJ-1 gene silencing enhances susceptibility to oxidative stress. These results could explain why the deletion of DJ-1 elicits the early onset of PD. The pathogenic L166P mutant of DJ-1 does not appear to play a pivotal role in ASK1-Daxx-dependent cell death. ${ }^{29}$ However, the L166P mutant of DJ-1 was identified as a JNK1-dependent cell death inducer, as it was shown to stimulate UV irradiation-induced cell death. ${ }^{21}$ Our findings also indicate that the L166P mutant of DJ-1 may also participate in the stimulation of the MEKK1-

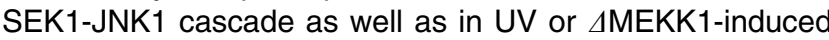
cell death, thereby suggesting that L166P may play a crucial role in JNK1-dependent cell death. Furthermore, the pathogenic L166P mutant of DJ-1 facilitates oxidative stress-induced cell death, despite its relatively low stability. The findings of this study indicate that DJ-1 may play a critical role in the control of this death pathway, a function which can be abrogated as the result of a PD-causing mutation.

\section{Materials and Methods}

Cell culture and transfection. Human embryonic kidney 293 cells were grown in Dulbecco's modified Eagle's medium (DMEM) supplemented with 10\% fetal bovine serum (FBS), penicillin $(100 \mathrm{U} / \mathrm{ml})$ and streptomycin $(100 \mu \mathrm{g} / \mathrm{ml})$. For plasmid DNA transfection, the cells were plated at a density of $2 \times 10^{6}$ cells $/ 100$ $\mathrm{mm}$ dish, grown overnight, then transfected with the appropriate expression vectors in the presence of the indicated combinations of plasmid DNAs, through the calcium phosphate and liposome method. For stable transfection, the HEK293 cells were transfected with pcDNA3 empty vector or pcDNA3-Flag-DJ-1, using Lipofectamineplus reagent. The total DNA amount was adjusted with carrier vector. After $48 \mathrm{~h}$ of transfection, the cells were replated at a dilution of $1 / 20$ and maintained in complete

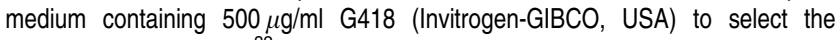
neomycin-resistant cells. ${ }^{32}$

Cloning and preparation of recombinant proteins. A murine MEKK1 gene and deletion mutants were constructed through standard PCR, and inserted into the bacterial expression vector, pGEX4T-1 (Amersham Pharmacia). The MEKK1 deletion mutants constructed in the present study were as follows: MEKK1N1 (amino-acid residues 1-396), MEKK1-N2 (amino-acid residues 397-821), MEKK1-N3 (amino-acid residues 822-1172), and MEKK1-N4 (amino-acid residues 1173-1493). The expression of the recombinant GST-MEKK1 proteins or pET30a expressing His6-tagged DJ-1 proteins within the transformed bacteria were induced using isopropyl- $\beta$-D-thiogalactopyranoside (Sigma). The GST-MEKK1 mutant proteins or His6-DJ-1 proteins were purified with GSH-agarose (Sigma) or $\mathrm{Ni}^{2+}$-NTA-agarose (Qiagen), respectively, in accordance with the manufacturer's instructions. The expression plasmids were verified by automatic DNA sequencing.

Immunocomplex kinase assay. To analyze the kinase activity, confluent cells were harvested and lysed in lysis buffer. ${ }^{40}$ Cell lysates were then subjected to $10 \mathrm{~min}$ of centrifugation at $12000 \times \mathrm{g}$ at $4^{\circ} \mathrm{C}$. The soluble fraction was incubated for $1 \mathrm{~h}$ with appropriate antibodies against the indicated protein kinases at $4^{\circ} \mathrm{C}$. The immunocomplexes were then coupled with protein G-agarose during an additional hour of incubation at $4^{\circ} \mathrm{C}$, after which they were pelleted through centrifugation. The immunopellets were rinsed three times with lysis buffer and then twice with $20 \mathrm{mM}$ HEPES, at a pH of 7.4. Immunocomplex kinase assays were conducted through the incubation of the immunopellets for $30 \mathrm{~min}$ at $30^{\circ} \mathrm{C}$ with $2 \mu \mathrm{g}$ of substrate proteins in $20 \mu \mathrm{l}$ reaction buffer containing $0.2 \mathrm{mM}$ sodium orthovanadate, $10 \mathrm{mM} \mathrm{MgCl}_{2}, 2 \mu \mathrm{Ci}$ $\left[\gamma^{32}\right.$ P]ATP, $20 \mathrm{mM}$ HEPES, and $\mathrm{pH}$ 7.4. The phosphorylated substrates were then visualized through SDS-PAGE, and quantified using a Fuji BAS 2500 phospholmager.

Two-dimensional gel electrophoresis. For 2DGE, $500 \mathrm{mg}$ of protein was separated first on $13 \mathrm{~cm}$ immobilized pH gradient (IPG; Amersham Biosciences) strips using $3.0 \pm 10.0$ linear gradients according to the manufacturer's instructions on the IPGPhor system (Amersham Biosciences). The second dimension was resolved on $10 \pm 20 \%$ SDS-PAGE gels and visualized using immunoblot. pl was calibrated using creatine phosphokinase carbamylated standards (Amersham Biosciences) and molecular weight using Precision prestained markers (Fermentas).

Reporter assay. The cells were lysed in chemiluminescent lysis buffer $(18.3 \%$ of $1 \mathrm{M} \mathrm{K}_{2} \mathrm{HPO}_{4}, 1.7 \%$ of $1 \mathrm{M} \mathrm{KH}_{2} \mathrm{PO}_{4}, 1 \mathrm{mM}$ phenylmethyl sulfonyl fluoride (PMSF), and $1 \mathrm{mM}$ dithiothreitol (DTT)) and assayed for luciferase activity with a luciferase assay kit (Promega). The activity of the luciferase reporter protein in the transfected cells was normalized in reference to the $\beta$-galactosidase activity in the same cells. $^{32}$

DJ-1 knockdown in cells. The siRNA targeting DJ-1 was used as described previously. ${ }^{19}$ Sham control or DJ-1 siRNA was transfected into HEK293 cells using Lipofectamine Plus reagent (Invitrogen), in accordance with the manufacturer's instructions.

Immunofluorescence staining. Assays were conducted as previously described with HEK293 cells plated at $1 \times 10^{5}$ cells per well onto cover slips (Fisher). A total of $0.5 \mu \mathrm{g}$ of appropriate DNA per well was then transfected using the Geneporter 2 system (Genetherapysystems). The transfected cells were fixed with $4 \%$ paraformaldehyde in phosphate-buffered saline (PBS), and then permeabilized with $0.1 \%$ Triton X-100 in PBS. Mouse anti-FlagM2 antibody (Sigma) and anti-HA antibody (Novus Biologicals) were used as the primary antibodies at a dilution of $1: 100$. Rhodamine Red or fluorescein-conjugated antimouse secondary antibody $(1: 100)$ was added, and then 4', 6-diamidino-2- 
phenylindole (DAPI) staining was applied. The stained cells were evaluated for localization through confocal microscopy (Leica TCS SP5). The final images were obtained and analyzed using confocal microscopy with LAS AF software (Leica).

In vitro binding assay. The recombinant GST fusion proteins were expressed in Escherichia coli strain BL21, using the pGEX system as indicated. The GST fusion proteins were then purified using glutathione-agarose beads (Sigma), in accordance with the manufacturer's instructions. Equal amounts of GST or GSTMEKK1 fusion proteins were incubated with the lysates of HEK293 cells, which had been transfected for $3 \mathrm{~h}$ with combinations of expression vectors at $4^{\circ} \mathrm{C}$, with rotation. After incubation, the beads were washed three times with ice-cold PBS, and boiled with $20 \mu \mathrm{l}$ of Laemmli sample buffer. The precipitates were separated through SDS-PAGE, and the pull-down proteins were detected through immunoblotting with specific antibodies.

Coimmunoprecipitation assays. The cells were lysed in $1 \mathrm{ml}$ of RIPA buffer for $30 \mathrm{~min}$ at $4^{\circ} \mathrm{C}$. After $20 \mathrm{~min}$ of centrifugation at $12000 \times \mathrm{g}$, the supernatants were subjected to immunoprecipitation with appropriate antibodies coupled to protein A-agarose beads. The resulting immunoprecipitates were washed three times with phosphate-buffered solution (PBS, pH 7.4). Laemmli sample buffer was then added to the immunoprecipitated pellets; the pellets were heated for $5 \mathrm{~min}$ at $95^{\circ} \mathrm{C}$ and analyzed through SDS-PAGE. Western blotting was conducted using the indicated antibodies. ${ }^{32}$

Apoptotic cell death assay using TUNEL staining. The TUNEL staining was carried out using the in situ cell death detection kit (Roche Molecular Biochemicals) according to the manufacturer's protocol as described previously. ${ }^{32}$ Briefly, cells in culture were fixed and fluorescein-12-dUTP was catalytically incorporated into the fragmented DNA at the $3^{\prime}-\mathrm{OH}$ by terminal deoxynucleotidyl transferase. The fluorescein-dUTP-labeled DNA was visualized directly by fluorescence microscopy using an excitation wavelength at $488 \mathrm{~nm}$. TUNELpositive cells were determined from cells for at least 200 nuclei.

Acknowledgements. We thank Hiroyoshi Ariga, Mark R Cookson, and Liang Tong for providing the DJ-1 clones and also we thank Drs. Sang Ryeul Lee and Tae-Hoon Lee for technical assistance. This work was supported by a grant from Brain Research Center of the 21st Century Frontier Research Program and Korea Research Foundation (MOEHRD, Basic Research Promotion Fund) (KRF-2005070-C00105) (H-S, Park) from the Republic of Korea.

1. Nagakubo D, Taira T, Kitaura $H$, Ikeda M, Tamai K, Iguchi-Ariga SM et al. DJ-1, a novel oncogene which transforms mouse NIH3T3 cells in cooperation with ras. Biochem Biophys Res Commun 1997; 231: 509-513.

2. Hod Y, Pentyala SN, Whyard TC, El-Maghrabi MR. Identification and characterization of a novel protein that regulates RNA-protein interaction. J Cell Biochem 1999; 72 : 435-444.

3. Wagenfeld A, Yeung $\mathrm{CH}$, Strupat K, Cooper TG. Shedding of a rat epididymal sperm protein associated with infertility induced by ornidazole and alpha-chlorohydrin. Biol Reprod 1998; 58: 1257-1265.

4. Welch JE, Barbee RR, Roberts NL, Suarez JD, Klinefelter GR. SP22: a novel fertility protein from a highly conserved gene family. J Androl 1998; 19: 385-393.

5. Bonifati V, Rizzu P, van Baren MJ, Schaap O, Breedveld GJ, Krieger E et al. Mutations in the DJ-1 gene associated with autosomal recessive early-onset parkinsonism. Science 2003; 299: 256-259.

6. Abou-Sleiman PM, Healy DG, Quinn N, Lees AJ, Wood NW. The role of pathogenic DJ-1 mutations in Parkinson's disease. Ann Neurol 2003; 54: 283-286.

7. Hague S, Rogaeva E, Hernandez D, Gulick C, Singleton A, Hanson M et al. Early-onset Parkinson's disease caused by a compound heterozygous DJ-1 mutation. Ann Neurol 2003; 54: 271-274.

8. Hedrich K, Djarmati A, Schafer N, Hering R, Wellenbrock C, Weiss PH et al. DJ-1 (PARK7) mutations are less frequent than Parkin (PARK2) mutations in early-onset Parkinson disease. Neurology 2004; 62: 389-394.

9. Moore DJ, Dawson VL, Dawson TM. Genetics of Parkinson's disease: what do mutations in DJ-1 tell us? Ann Neurol 2003; 54: 281-282.

10. Honbou K, Suzuki NN, Horiuchi M, Niki T, Taira T, Ariga $\mathrm{H}$ et al. The crystal structure of DJ1, a protein related to male fertility and Parkinson's disease. J Biol Chem 2003; 278 : 31380-31384.

11. Tao X, Tong L. Crystal structure of human DJ-1, a protein associated with early onset Parkinson's disease. J Biol Chem 2003; 278: 31372-31379.
12. Wilson MA, Collins JL, Hod Y, Ringe D, Petsko GA. The 1.1-A resolution crystal structure of DJ-1, the protein mutated in autosomal recessive early onset Parkinson's disease. Proc Natl Acad Sci U S A 2003; 100: 9256-9261.

13. Clements CM, McNally RS, Conti BJ, Mak TW, Ting JP. DJ-1, a cancer- and Parkinson's disease-associated protein, stabilizes the antioxidant transcriptional master regulator Nrf2. Proc Natl Acad Sci U S A 2006; 103: 15091-15096.

14. Meulener MC, Xu K, Thomson L, Ischiropoulos H, Bonini NM. Mutational analysis of DJ-1 in Drosophila implicates functional inactivation by oxidative damage and aging. Proc Natl Acad Sci U S A 2006; 103: 12517-12522.

15. Canet-Aviles RM, Wilson MA, Miller DW, Ahmad R, McLendon C, Bandyopadhyay S et al. The Parkinson's disease protein DJ-1 is neuroprotective due to cysteine-sulfinic acid-driven mitochondrial localization. Proc Natl Acad Sci U S A 2004; 101: 9103-9108.

16. Mitsumoto A, Nakagawa Y. DJ-1 is an indicator for endogenous reactive oxygen species elicited by endotoxin. Free Radic Res 2001; 35: 885-893.

17. Mitsumoto A, Nakagawa Y, Takeuchi A, Okawa K, Iwamatsu A, Takanezawa Y. Oxidized forms of peroxiredoxins and DJ-1 on two-dimensional gels increased in response to sublethal levels of paraquat. Free Radic Res 2001; 35: 301-310.

18. Srisomsap $C$, Subhasitanont $P$, Otto A, Mueller EC, Punyarit $P$, Wittmann-Liebold $B$ et al. Detection of cathepsin $B$ up-regulation in neoplastic thyroid tissues by proteomic analysis. Proteomics 2002; 2: 706-712.

19. Taira $T$, Saito $Y$, Niki T, Iguchi-Ariga SM, Takahashi K, Ariga H. DJ-1 has a role in antioxidative stress to prevent cell death. EMBO Rep 2004; 5: 213-218.

20. Yokota T, Sugawara K, Ito K, Takahashi R, Ariga H, Mizusawa H. Down regulation of DJ-1 enhances cell death by oxidative stress, ER stress, and proteasome inhibition. Biochem Biophys Res Commun 2003; 312: 1342-1348.

21. Shinbo $Y$, Niki T, Taira T, Ooe H, Takahashi-Niki K, Maita $C$ et al. Proper SUMO-1 conjugation is essential to DJ-1 to exert its full activities. Cell Death Differ 2006; 13 96-108.

22. Gorner K, Holtorf E, Odoy S, Nuscher B, Yamamoto A, Regula JT et al. Differential effects of Parkinson's disease-associated mutations on stability and folding of DJ-1. J Biol Chem 2004; 279: 6943-6951.

23. Olzmann JA, Brown K, Wilkinson KD, Rees HD, Huai Q, Ke H et al. Familial Parkinson's disease-associated L166P mutation disrupts DJ-1 protein folding and function. J Biol Chem 2004; 279: 8506-8515.

24. Moore DJ, Zhang L, Dawson TM, Dawson VL. A missense mutation (L166P) in DJ-1, linked to familial Parkinson's disease, confers reduced protein stability and impairs homooligomerization. J Neurochem 2003; 87: 1558-1567.

25. Miller DW, Ahmad R, Hague S, Baptista MJ, Canet-Aviles R, McLendon C et al. L166P mutant DJ-1, causative for recessive Parkinson's disease, is degraded through the ubiquitin-proteasome system. J Biol Chem 2003; 278: 36588-36595.

26. Macedo MG, Anar B, Bronner IF, Cannella M, Squitieri F, Bonifati V et al. The DJ-1L166P mutant protein associated with early onset Parkinson's disease is unstable and forms higher-order protein complexes. Hum Mol Genet 2003; 12: 2807-2816.

27. Kim RH, Peters M, Jang Y, Shi W, Pintilie M, Fletcher GC et al. DJ-1, a novel regulator of the tumor suppressor PTEN. Cancer Cell 2005; 7: 263-273.

28. Yang Y, Gehrke S, Haque ME, Imai Y, Kosek J, Yang L et al. Inactivation of Drosophila DJ1 leads to impairments of oxidative stress response and phosphatidylinositol 3-kinase/Akt signaling. Proc Natl Acad Sci U S A 2005; 102: 13670-13675.

29. Junn E, Taniguchi H, Jeong BS, Zhao X, Ichijo H, Mouradian MM. Interaction of DJ-1 with Daxx inhibits apoptosis signal-regulating kinase 1 activity and cell death. Proc Natl Acad Sci U S A 2005; 102: 9691-9696.

30. Ip YT, Davis RJ. Signal transduction by the c-Jun N-terminal kinase (JNK)-from inflammation to development. Curr Opin Cell Biol 1998; 10: 205-219.

31. Verheij M, Bose R, Lin XH, Yao B, Jarvis WD, Grant $S$ et al. Requirement for ceramide-initiated SAPK/JNK signalling in stress-induced apoptosis. Nature 1996; 380: 75-79.

32. Park HS, Lee JS, Huh SH, Seo JS, Choi EJ. Hsp72 functions as a natural inhibitory protein of c-Jun N-terminal kinase. EMBO J 2001; 20: 446-456.

33. Derijard B, Hibi M, Wu IH, Barrett T, Su B, Deng T et al. JNK1: a protein kinase stimulated by UV light and $\mathrm{Ha}$-Ras that binds and phosphorylates the c-Jun activation domain. Cell 1994; 76: 1025-1037.

34. Baek SH, Ohgi KA, Rose DW, Koo EH, Glass CK, Rosenfeld MG. Exchange of N-CoR corepressor and Tip60 coactivator complexes links gene expression by NF-kappaB and beta-amyloid precursor protein. Cell 2002; 110: 55-67.

35. Lee FS, Hagler J, Chen ZJ, Maniatis T. Activation of the IkappaB alpha kinase complex by MEKK1, a kinase of the JNK pathway. Cell 1997; 88: 213-222.

36. Cassarino DS, Halvorsen EM, Swerdlow RH, Abramova NN, Parker Jr WD, Sturgill TW et al. Interaction among mitochondria, mitogen-activated protein kinases, and nuclear factor-kappaB in cellular models of Parkinson's disease. J Neurochem 2000; 74: 1384-1392.

37. Chun HS, Gibson GE, DeGiorgio LA, Zhang H, Kidd VJ, Son JH. Dopaminergic cell death induced by MPP(+), oxidant and specific neurotoxicants shares the common molecular mechanism. J Neurochem 2001; 76: 1010-1021.

38. Saporito MS, Thomas BA, Scott RW. MPTP activates c-Jun NH(2)-terminal kinase (JNK) and its upstream regulatory kinase MKK4 in nigrostriatal neurons in vivo. J Neurochem 2000; 75: 1200-1208. 
39. Xia XG Harding T, Weller M, Bieneman A, Uney JB, Schulz JB. Gene transfer of the JNK interacting protein-1 protects dopaminergic neurons in the MPTP model of Parkinson's disease. Proc Natl Acad Sci U S A 2001; 98: 10433-10438.
40. Park HS, Huh SH, Kim MS, Lee SH, Choi EJ. Nitric oxide negatively regulates c-Jun $\mathrm{N}$ terminal kinase/stress-activated protein kinase by means of S-nitrosylation. Proc Natl Acad Sci U S A 2000; 97: 14382-14387.

Supplementary Information accompanies the paper on Cell Death and Differentiation website (http://www.nature.com/cdd) 